\title{
Difierence of Sodium Currents between Pediatric and Adult Human Atrial Myocytes: Evidence for Developmental Changes of Sodium Channels
}

\author{
Benzhi Cai ${ }^{*}$, Xiaoqin Mu ${ }^{1^{*}}$, Dongmei Gong ${ }^{1}$, Shulin Jiang ${ }^{3}$, Jianping Li ${ }^{1}$, Qingxin Meng ${ }^{3}$, Yunlong Bai ${ }^{1}$, \\ Yanju Liu 1, Xinyue Wang 1, Xueying Tan 1, Baofeng Yang 1,2, Yanjie Lu 1,2 $\bowtie$
}

1. Department of Pharmacology (the State-Province Key Laboratories of Biomedicine- Pharmaceutics of China, Key Laboratory of Cardiovascular Research, Ministry of Education), Harbin Medical University, Harbin 150081, China.

2. Cardiovascular Research Institute, Harbin Medical University, Harbin 150081, China.

3. Department of Cardiosurgery, Second Affiliated Hospital of Harbin Medical University, Harbin 150081, China.

* The first two authors made equal contribution to this research.

Corresponding author: Yanjie Lu, MD, PhD; Department of Pharmacology (the State-Province Key Laboratories of Biomedicine-Pharmaceutics of China), Harbin Medical University, Harbin 150081, China. Fax: 86-451-86675769; Tel: 86-451-86671354; E-mail: Yjlu86@yahoo.com

(C) Ivyspring International Publisher. This is an open-access article distributed under the terms of the Creative Commons License (http://creativecommons.org/ licenses/by-nc-nd/3.0/). Reproduction is permitted for personal, noncommercial use, provided that the article is in whole, unmodified, and properly cited.

Received: 2010.12.16; Accepted: 2011.05.25; Published: 2011.06.01

\begin{abstract}
Voltage-gated calcium currents and potassium currents were shown to undergo developmental changes in postnatal human and animal cardiomocytes. However, so far, there is no evidence whether sodium currents also presented the developmental changes in postnatal human atrial cells. The aim of this study was to observe age-related changes of sodium currents between pediatric and adult atrial myocytes. Human atrial myocytes were acutely isolated and the whole-cell patch clamp technique was used to record sodium currents isolated from pediatric and adult atrial cardiomocytes. The peak amplitude of sodium currents recorded in adult atrial cells was significantly larger than that in pediatric atrial myocytes. However, there was no significant difference of the activation voltage for peak sodium currents between two kinds of atrial myocytes. The time constants for the activation and inactivation of sodium currents were smaller in adult atria than pediatric atria. The further study revealed that the voltage-dependent inactivation of sodium currents were more slow in adult atrial cardiomyocytes than pediatric atrial cells. A significant difference was also observed in the recovery process of sodium channel from inactivation. In summary, a few significant differences were demonstrated in sodium currents characteristics between pediatric and adult atrial myocytes, which indicates that sodium currents in human atria also undergo developmental changes.
\end{abstract}

Key words: sodium channel; postnatal development; patch clamp; cardiomocytes.

\section{Introduction}

Sodium currents are an important transmembrane current and responsible for the formation of action potential duration in a variety of cells such as cardiomocytes, neurons, and vascular smooth muscle cells. [1-3]. The structural or functional alteration of sodium channel has been showed to trigger or aggravate the arrhythmias and other heart diseases, such as LQT syndrome and Brugada syndrome [3-7]. Though lots of studies revealed the important roles of sodium currents in human and animals cardio- 
mocytes, the information about the developmental changes of sodium currents in postnatal human hearts was limited [8-9].

During the past decades, the relatively large body of data has documented that there are significant developmental changes in the density and characteristics of calcium currents and potassium currents observed in mammalian cardiac tissues [10-15]. For instance, it was reported that transient outward potassium currents both in atrial and ventricular cardiomocytes underwent a progressive increase in postnatal mouse [13]. Calcium currents are also observed much larger in adult hearts than pediatric hearts [16]. Likewise, the mRNA expression and the channel kinetics of sodium channel also display the age-relevant changes in mouse and canine hearts [17-18]. Especially recently, a large-scale analysis of gene expression of cardiac ionic channels showed that SCN5A expression was remarkably increased during postnatal development in mouse [17]. However, whether sodium currents also undergo the developmental increase from pediatric to adult hearts remain unknown. The present study was carried out to investigate the difference of sodium currents between pediatric and adult hearts, which will help to provide the evidence that sodium channels underwent postnatal development in human atria just like other currents.

\section{Materials and methods}

\section{Isolation of human atrial myocytes}

Atrial samples were obtained from human right atrial appendage of six adult patients with rheumatic heart diseases $(42.5 \pm 1.3$ years old) undergoing cardiopulmonary bypass, and five pediatric patients with congenital heart diseases $(3.4 \pm 1.2$ years old) undergoing cardiopulmonary bypass. All the experimental procedures were approved by the ethics committee of Harbin Medical University, with informed consent of these patients, and performed in accordance with the principles outlined in the Declaration of Helsinki. All the patients were in normal sinus rhythm with no record of atrial arrhythmias. Human atrial specimens were immediately placed in $\mathrm{KB}$ solution gassed with oxygen $\left(95 \% \mathrm{O}_{2}, 5 \% \mathrm{CO}_{2}\right)$ at $4^{\circ} \mathrm{C}$ from surgical excision. The method to isolate human atrial myocytes is just as described previously with some modifications [9]. In brief, atrial samples were cut into chunks and washed three times in oxygenated $\mathrm{Ca}^{2+}$ free Tyrode's solution at $37^{\circ} \mathrm{C}$, and then was incubated in $10 \mathrm{~mL}$ $\mathrm{Ca}^{2+}$ free Tyrode's solution containing collagenase type II and BSA for $40 \mathrm{~min}$ at $37^{\circ} \mathrm{C}$. Following, the tissues were transferred to fresh $10 \mathrm{~mL} \mathrm{Ca}^{2+}$-free Tyrode's solution containing collagenase type II. The isolation was finished when microscopic examination revealed a satisfactory number of intact cardiomyocytes. Human atrial myocytes were collected and resuspended in $\mathrm{KB}$ solution and then kept at $4^{\circ} \mathrm{C}$ before they were used.

\section{Experimental solution}

The $\mathrm{KB}$ solution contained (in $\mathrm{mM}$ ) glutamic acid 70, taurine $15, \mathrm{KCl} 30, \mathrm{KH}_{2} \mathrm{PO}_{4} 10$, HEPES 10, $\mathrm{MgCl}_{2} 0.5$, glucose 10, and EGTA 0.5 (pH adjusted to 7.4 by $\mathrm{KOH}$ ). The Tyrode's solution contained (in $\mathrm{mM}) \mathrm{NaCl}$ 136, $\mathrm{KCl}$ 5.4, $\mathrm{CaCl}_{2}$ 1.8, $\mathrm{MgCl}_{2}$ 1.0, $\mathrm{NaH}_{2} \mathrm{PO}_{4}$ 0.33, HEPES 10, and glucose $10(\mathrm{pH}$ adjusted to 7.4 with $\mathrm{NaOH}$ ). The external solution for recording sodium currents contained (in $\mathrm{mM}$ ) $\mathrm{CsCl}$ 120, $\mathrm{NaCl} 25, \mathrm{HEPES} 5, \mathrm{MgCl}_{2}$ 1.0, $\mathrm{CaCl}_{2}$ 1.0, and Glucose10 ( $\mathrm{pH}$ adjusted to 7.4 with $\mathrm{CsOH}$ ). The internal solution for sodium currents recordings contained (in $\mathrm{mM}$ ) $\mathrm{CsCl} 20, \mathrm{CsF} 110, \mathrm{NaCl} 5$, HEPES 5, EGTA 10, and MgATP 5 (pH adjusted to 7.2 with $\mathrm{CsOH})$. For all recordings, calcium channel blocker verapamil $10 \mu \mathrm{M}$ was included in the external solution to minimize contamination of calcium currents.

\section{Patch clamping}

A small drop of KB solution containing isolated human atrial cardiomyocytes was placed in a 1-mL chamber mounted on the stage of an inverted microscope. After human atrial cells adhered to the bottom of the chamber, the external solution for recording sodium currents was used to continuously superfuse these cells. Only rod-shaped atrial myocytes with clear cross-striation were selected for current recording in the present study. The whole-cell patch-clamp techniques were used to record sodium currents in the voltage-clamp mode by an Axopatch 200B amplifier (Axon Instruments). When filled with pipette solution the electrodes had tip resistances from 2 to $4 \mathrm{M} \Omega$. The potential of the pipette was zeroed before contacting the cell membrane in the bath solution. Voltage command pulses were generated by a 12-bit digital-to-analog converter controlled by pClamp 9.0 software (Axon Instruments). After a gigaohm seal formation, the membrane was ruptured to form the whole-cell configuration. The capacitance and series resistance were compensated and sodium currents data were expressed as current density $(\mathrm{pA} / \mathrm{pF})$ by normalizing the current to its capacitance for each atrial myocytes. Sodium currents $\left(\mathrm{I}_{\mathrm{Na}}\right)$ were recorded at room temperature $\left(18 \pm 1^{\circ} \mathrm{C}\right)$. 


\section{Statistical analysis}

All the data are presented as mean \pm SEM. Statistical analysis was performed by ANOVA and the student t-test. Boltzmann function was used to fit the voltage-dependent activation and inactivation curve of sodium currents. The mono-exponential function was used to determine the recovery time constants of sodium currents from inactivation. A two-tailed value of $\mathrm{P}<0.05$ was taken to indicate statistical significance.

\section{Results}

\section{Comparison of sodium currents in human atrial myocytes from pediatrics and adults}

Sodium currents were elicited by a series of 100-ms depolarizing test potentials between $-60 \mathrm{mV}$ to $+40 \mathrm{mV}$ with $10 \mathrm{mV}$ step at a holding potential of -80 $\mathrm{mV}$. The average capacitance was $49.6 \pm 3.1 \mathrm{pF}$ in pediatric atrial myocytes, and $71.0 \pm 5.7 \mathrm{pF}$ in adult atrial myocytes. Fig. 1A showed typical superimposed traces of sodium currents recorded in pediatrics and adults atrial cells. The peak density of sodium currents at $-30 \mathrm{mV}$ was significantly larger in adults atrial cells $(-46.67 \pm 2.36 \mathrm{pA} / \mathrm{pF}, \mathrm{n}=13)$ than pediatrics atrial cells $(-31.82 \pm 1.91 \mathrm{pA} / \mathrm{pF}, \mathrm{n}=10) \quad(\mathrm{P}<0.05)$. Fig. 1B demonstrated the I-V relationship curve of sodium currents recorded in pediatric and adult atrial myocytes. There was a significant difference of the peak amplitude of sodium currents between two kinds of atrial cells $(\mathrm{n}=13$ and 10 , respectively, $\mathrm{P}<0.05)$. However, the maximum activation voltage for peak sodium currents in adult atrial cells did not obviously differ from pediatric atrial myocytes.

\section{The time-dependent kinetic properties of so- dium currents in pediatrics and adults atrial myocytes}

Fig. 2 displayed the time-dependent kinetic properties of sodium currents in two kinds of atrial cells. In order to calculate the time constants for activation ( $\left.\tau_{\text {act }}\right)$ and inactivation ( $\left.\tau_{\text {inact }}\right)$, a single exponential function was used to fit the descending phase of sodium currents traces, and a bi-exponential function to fit the rising phase of sodium currents traces, respectively. Fig. $2 \mathrm{~B}$ and $2 \mathrm{C}$ showed the comparison of $\tau_{\text {act }}$ and $\tau_{\text {inact }}$ of sodium currents between pediatric and adult atrial cells. The activation and inactivation constants were remarkably smaller in adult atrial cells, compared with pediatric cells. At $-30 \mathrm{mV}$, the $\tau_{\text {act }}$ was $1.01 \pm 0.17 \mathrm{~ms}$ in adult atrial cells and $1.79 \pm 0.15 \mathrm{~ms}$ in pediatric atrial cells $(\mathrm{n}=13$ and 10, respectively, $\mathrm{P}<0.05$ ). Similarly, the $\tau_{\text {inact.f }}$ (the fast component of inactivation) and $\tau_{\text {inact.s }}$ (the slow component of inactivation) were $1.33 \pm 0.23 \mathrm{~ms}$ and $5.69 \pm 0.50 \mathrm{~ms}$ for adult atrial cardiomyocytes and $2.33 \pm 0.34 \mathrm{~ms}$ and $7.93 \pm 0.68$ $\mathrm{ms}$ for pediatric atrial cells, respectively $(\mathrm{n}=13$ and 10 , respectively, $\mathrm{P}<0.05)$.
A

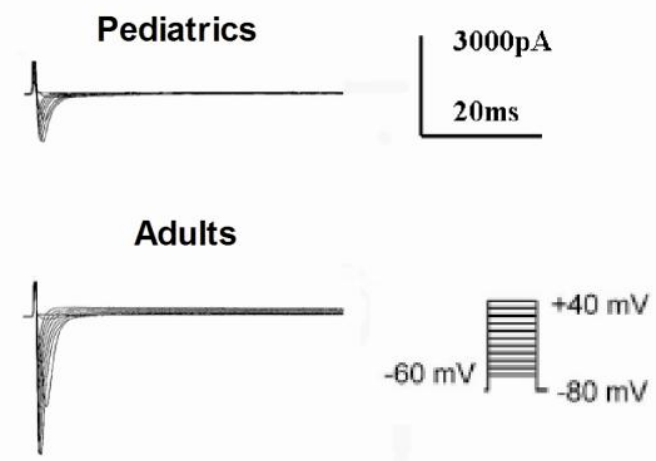

B

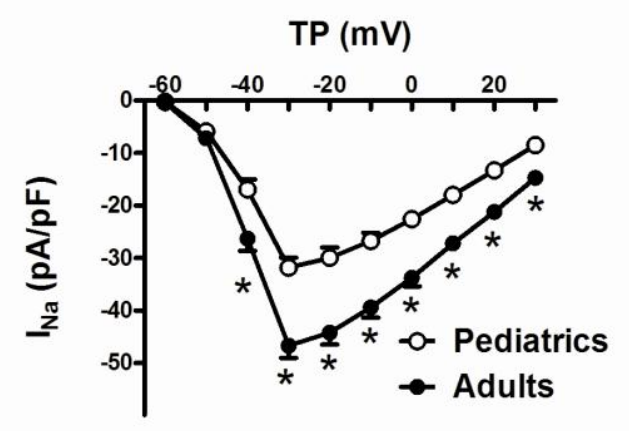

Fig. 1. Representative traces of sodium currents recorded in adult and pediatric atrial cells. (A) Sodium currents was elicited by 100 -ms test pulses in $10 \mathrm{mV}$ increments from a holding potential of $-80 \mathrm{mV}$ to potentials between -60 and $+40 \mathrm{mV}$. The I-V relationship curve of sodium currents recorded in pediatric and adult atrial cells ( $\mathrm{n}=10$ and 13 , respectively) (B). The amplitudes of sodium currents were normalized to cell capacitance and presented as mean values at different test potentials. * represents $\mathrm{P}<0.05$. 

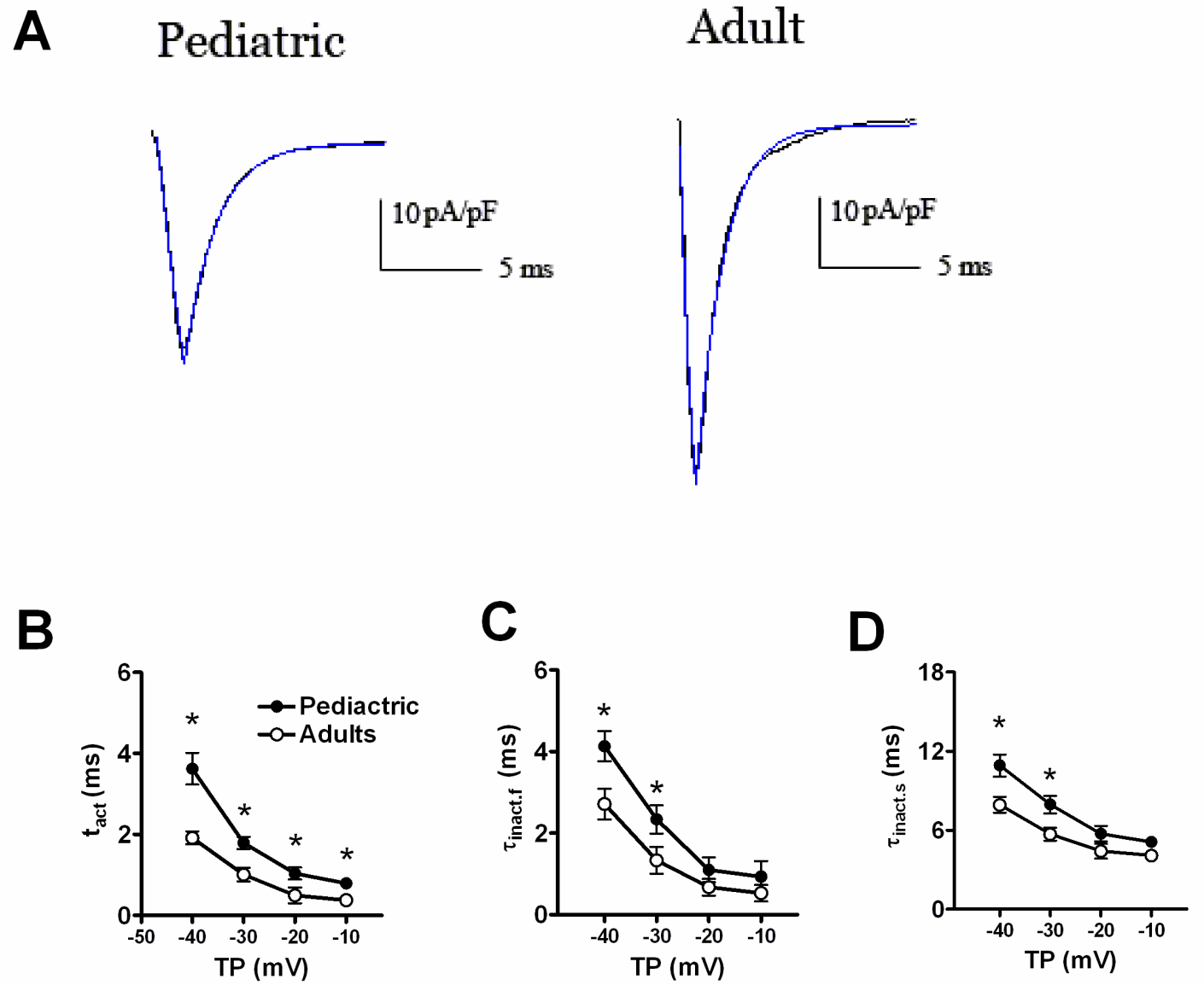

Fig. 2. The time-dependent properties of sodium currents recorded in adult and pediatric atrial myocytes. The single exponential function was used to fit the descending of sodium currents traces. The bi-exponential function was used to fit the ascending phase of sodium currents traces (A). Comparison of the activation (B) and inactivation (C, D) time constants of sodium currents between adult and pediatric atrial myocytes ( $n=13$ and 10 , respectively). ${ }^{*}$ means $\mathrm{P}<0.05$.

\section{The voltage-dependent properties of sodium currents in pediatric and adult atrial cells}

The voltage-dependent activation of sodium currents were recorded by using a $50 \mathrm{~ms}$ prepulse of $-100 \mathrm{mV}$ followed by a series of $100 \mathrm{~ms}$ test pulses between -70 and $+30 \mathrm{mV}$. The $V_{1 / 2}$ (the voltage at half activation) values were $-38.63 \pm 0.32 \mathrm{mV}$ in adult atrial myocytes and $-37.01 \pm 1.18 \mathrm{mV}$ in pediatric atrial myocytes ( $\mathrm{n}=10$ and 9, respectively, $\mathrm{P}>0.05$ ) (Fig. 3A). Furthermore, the slope factors $(k)$ were $5.07 \pm 0.28$ in adults and $7.51 \pm 1.01 \mathrm{mV}$ in pediatrics, $(\mathrm{n}=10$ and 9, respectively, $\mathrm{P}>0.05)$. This implies that there is no significant difference of voltage-dependent activation of sodium currents. The voltage-dependent inactivation properties were determined using a two-step protocol as shown in Fig. 3B. Compared with adult atrial cells, the inactivation curve of sodium currents in adult atrial cells shifted toward positive potential
(Fig. 3B). The $V_{1 / 2}$ values were $-60.00 \pm 0.99 \mathrm{mV}$ in adult atrial myocytes and $-71.68 \pm 0.62 \mathrm{mV}$ in pediatric atrial myocytes $(\mathrm{n}=10$ and 9 , respectively, $\mathrm{P}<0.05)$. It suggests that cardiac sodium channel is more easily inactivated by voltage stimuli in pediatric than adult atrial cells. The slope factor of the voltage-dependent steady-state inactivation curve of sodium currents was $6.15 \pm 0.76 \mathrm{mV}$ in adult atrial myocytes and $5.53 \pm 0.39 \mathrm{mV}$ in pediatric atrial myocytes, respectively ( $\mathrm{n}=10$ and 9, respectively, $\mathrm{P}>0.05$ ). Fig. 3C illustrated the time-dependent recovery curve of sodium currents from inactivation using a paired-pulse protocol. There was a significant difference of recovery time constants of sodium currents between adult and pediatric atrial myocytes $(\tau=13.39 \pm 1.57$ and $8.91 \pm 0.79 \mathrm{~ms}, \mathrm{n}=10$ and 9 , respectively, $\mathrm{P}<0.05)$, which indicates that the recovery process of sodium channel from inactivation is much faster in pediatric than adult cardiomocytes. 
A
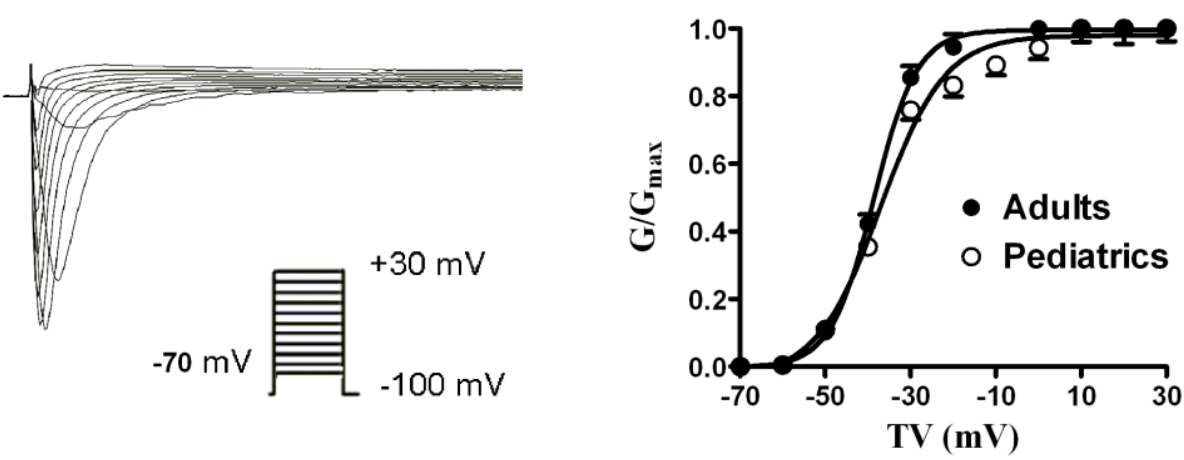

B
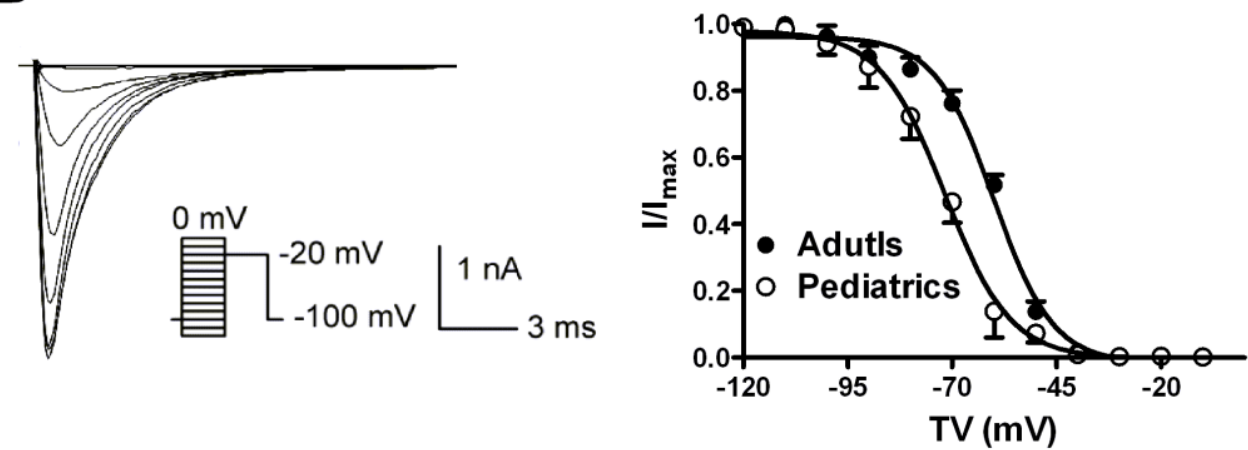

C
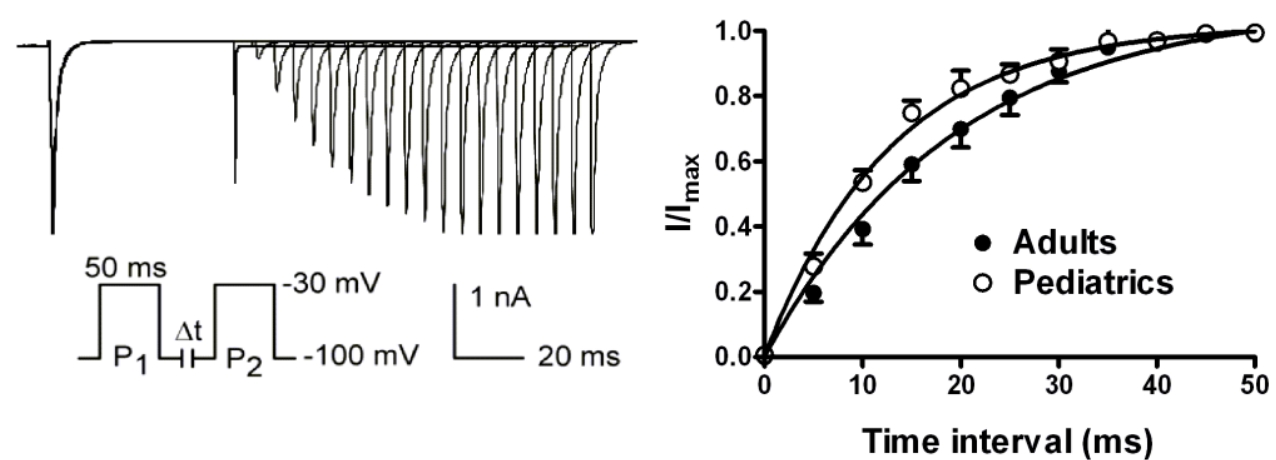

Fig. 3. The voltage-dependent kinetics of sodium currents recorded in adult and pediatric atrial myocytes. The voltage-dependent activation (A) and inactivation (B) of sodium currents recorded in atrial cells isolated from pediatric and adult patients ( $n=9$ and 10, respectively). The time-dependent recovery of sodium currents (C) from inactivation was studied using paired-pulse protocols.

\section{Discussion}

The main findings of the present study were that there were significant differences of sodium current properties between pediatric and adult atrial myocytes, which firstly provided the evidence for the postnatal development of sodium currents in human atrial cells.
Sodium currents play a key role in the initiation and rapid repolarization of action potential duration in many types of cells [1-3]. Cardiac sodium channels are mainly composed of pore-forming a-subunit such as Nav1.5 (SCN5A) and auxiliary $\beta$-subunits $[8$, 19-20]. The abnormalities of cardiac sodium channel subunits provide the pathological substrate for severe Long QT syndrome, fetal ventricular arrhythmias or 
atrial arrhythmias [3-7, 20-21]. In a previous study, we compared the characteristic of sodium currents between right atrial appendage and atrial septum of the same heart, and found smaller sodium currents in right atrial appendage compared with atrial septum, which allowed for faster conduction in these cells than right atrial appendage [9]. In summary, a lot of studies have revealed that sodium currents are very important for the physiological functions of human and animals' hearts, but whether sodium currents undergo the developmental changes in postnatal human hearts is completely unknown.

It is well known that potassium currents played an important role in the regulation of cardiac electrophysiological properties and the pathogenesis of heart diseases [22-23]. Notably, it was found that there are obviously developmental changes of potassium channels currents in animal hearts [13-15, 24]. Wang et al uncovered that adult atrial cells exhibited a larger current density and faster recovery decoy of transient outward potassium currents compared with neonatal atrial myocytes, which provided the evidence for developmental changes of potassium currents in human atrium [24]. The upregulation of $\mathrm{Kv} 4.2$ and $\mathrm{Kv} 4.3$ mRNAs were shown to contribute to thyroid hormone-induced the development of transient outward potassium currents in rat ventricle [14]. Inward rectifier potassium currents and ATP-sensitive potassium currents also displayed a development increase from gestation day 10 to neonatal day 30 [15]. The inactivation process of calcium currents in pediatric human atria cells was approximately 2 -fold faster than adults, which suggested there were age-relevant changes in calcium currents inactivation [16]. Sodium channel encoding genes including Nav1.5 were more expressed in adult hearts than immature hearts [17]. These developmental changes in sodium channel subunits may contribute to changes in macroscopic sodium currents during development [25]. Recently, a large-scale analysis of gene expression of ion channels showed that SCN5A expression was increased during postnatal development in the mouse heart [17]. However, whether sodium channels also undergo the developmental increase between pediatric and adult hearts remain unknown.

In the present study, we found that sodium currents were larger in adult atrial myocytes than pediatric atrial myocytes. This finding was in accordance with the increase of sodium channel mRNA in the development of mouse heart [17], indicating the developmental changes of sodium currents. We further investigated the difference of time constants of sodium currents between two types of atrial cells and found that the activation and inactivation time con- stants in adult atrial cells were smaller than that in pediatric atrial cells. It indicates that sodium channel is closed more slowly in pediatric atrial myocytes than adults, and the number of sodium ion flowing into cytoplasm through single sodium channel tend to be larger in pediatric atrial cells than adults at the late stage of channel inactivation, which is likely to cause the delay of membrane early repolarization and the prolongation of action potential duration. Consistently, it was previously reported that action potential duration was significant longer in infant atrial cells than adults during the early period of membrane potential repolarization [24, 26]. Similarly, the difference of voltage-dependent activation and inactivation of sodium channels were studied and adult atrial cells exhibited the similar voltage-dependent activation and more slow voltage-dependent inactivation compared with pediatric atrial cells. The delay of the voltage-dependant inactivation will cause much long opening time for sodium channel in hearts, which might contribute to the increase of sodium currents. Furthermore, the faster recovery process of sodium channel from inactivation in pediatric atrial cells than adults would promote sodium channels more frequently opened in a certain period of time and partially provided a rational explanation for the faster heart beating in pediatrics.

Taken together, adult atrial myocytes exhibited significantly different characteristics of sodium currents from pediatrics, including a larger current density, and slower inactivation and recovery. These findings provide the experimental evidence for the postnatal development of sodium currents in human atrial cells.

\section{Acknowledgments}

This work was supported by the Special Postdoctoral Scientific Funds of China (201003461), the National Natural Science Fund of China (30900601/30971252) and the Dr. Wu Lien-Teh (Wu Lian-De) Youth Foundation of Harbin Medical University.

\section{Conflict of Interests}

The authors have declared that no conflict of interest exists.

\section{References}

1. Vacher H, Mohapatra DP, Trimmer JS. Localization and targeting of voltage-dependent ion channels in mammalian central neurons. Physiol Rev 2008; 88:1407-1447.

2. Van Wart A, Boiko T, Trimmer JS, Matthews G. Novel clustering of sodium channel Nav1.1 with ankyrin-G and neurofascin at discrete sites in the inner plexiform layer of the retina. Mol Cell Neurosci 2005; 28:661-673. 
3. Zhang T, Yong SL, Tian XL, Wang QK. Cardiac-specific overexpression of SCN5A gene leads to shorter $\mathrm{P}$ wave duration and PR interval in transgenic mice. Biochem Biophys Res Commun 2007; 355:444-450.

4. Tian XL, Yong SL, Wan X, Wu L, Chung MK, Tchou PJ, Rosenbaum DS, Van Wagoner DR, Kirsch GE, Wang Q. Mechanisms by which SCN5A mutation N1325S causes cardiac arrhythmias and sudden death in vivo. Cardiovasc Res 2004; 61: 256-267.

5. Takeo S, Tanonaka K. $\mathrm{Na}^{+}$overload-induced mitochondrial damage in the ischemic heart. Can J Physiol Pharmacol 2004; 82:1033-1043

6. Cai BZ, Shan LC, Gong DM, Pan ZW, Ai J, Xu CQ, Lu YJ, Yang BF. Homocysteine modulates sodium currents in human atrial myocytes. Toxicology 2009; 256: 201-206.

7. Verkerk AO, Wilders R, van Borren MM, Tan HL. Is sodium current present in human sinoatrial node cells? Int J Biol Sci. 2009; 5:201-204.

8. Abriel H. Cardiac sodium channel $\mathrm{Na}_{\mathrm{v}} 1.5$ and interacting proteins: Physiology and pathophysiology. J Mol Cell Cardiol 2010; 48:2-11.

9. Gong DM, Zhang Y, Cai BZ, Meng QX, Jiang SL, Li X, Shan LC, Liu YY, Qiao GF, Lu YJ, Yang BF. Characterization and comparison of $\mathrm{Na}^{+}, \mathrm{K}^{+}$and $\mathrm{Ca}^{2+}$ currents between myocytes from human atrial right appendage and atrial septum. Cell Physiol Biochem 2008; 21:385-394.

10. Trépanier-Boulay V, Lupien MA, St-Miche C, Fiset C. Postnatal development of atrial repolarization in the mouse. Cardiovasc Res 2004; 64: 84-93.

11. Kobayashi T, Yamada $Y$, Nagashima M, Seki S, Tsutsuura M, Ito Y, Sakuma I, Hamada H, Abe T, Tohse N. Contribution of KChIP2 to the developmental increase in transient outward current of rat cardiomyocytes. J Mol Cell Cardiol. 2003; 35(9):1073-1082.

12. Leuranguer V, Monteil A, Bourinet E, Dayanithi G, Nargeot J. T-type calcium currents in rat cardiomyocytes during postnatal development: contribution to hormone secretion. Am J Physiol Heart Circ Physiol 2000; 279: H2540-H2548.

13. Wang L, Duff HJ. Developmental changes in transient outward current in mouse ventricle. Circ Res 1997; 81:120-127.

14. Shimoni Y, Fiset C, Clark RB, Dixon JE, McKinnon D, Giles WR. Thyroid hormone regulates postnatal expression of transient K+ channel isoforms in rat ventricle. J Physiol. 1997;500 ( Pt 1):65-73.

15. Xie LH, Takano M, Noma A. Development of inwardly rectifying $\mathrm{K}^{+}$channel family in rat ventricular myocytes. Am J Physiol 1997; 272: H1741-H1750.

16. Roca TP, Pigott JD, Clarkson CW, Jr Crumb WJ. L-type calcium current in pediatric and adult human atrial myocytes: evidence for developmental changes in channel inactivation. Pediatr Res 1996; 40:462-468.

17. L Harrell MD, Harbi S, Hoffman JF, Zavadil J, Coetzee WA. A Large-scale analysis of ion channel gene expression in the mouse heart during perinatal development. Physiol Genomics 2007; 28:273-283.

18. Baba S, Dun W, Hirose M, Boyden PA. Sodium current function in adult and aged canine atrial cells. Am J Physiol Heart Circ Physiol 2006; 291: H756-H761.

19. Ruan Y, Denegri M, Liu N, Bachetti T, Seregni M, Morotti S, Severi S, Napolitano C, Priori SG. Trafficking defects and gating abnormalities of a novel SCN5A mutation question gene-specific therapy in long QT syndrome type 3. Circ Res 2010; 106:1374-1383.

20. Wang DW, Crotti L, Shimizu W, Pedrazzini M, Cantu F, P Filippo De, Kishiki K, Miyazaki A, Ikeda T, Schwartz PJ, Jr George AL. Malignant perinatal variant of long-QT syndrome caused by a profoundly dysfunctional cardiac sodium channel. Circ Arrhythm Electrophysiol 2008; 1: 370-378.

21. Yue L, Melnyk P, Gaspo R, Wang Z, Nattel S. Molecular mechanisms underlying ionic remodeling in a dog model of atrial fibrillation. Circ Res 1999; 84:776-784.

22. Cai BZ, Gong DM, Liu Y, Pan ZW, Xu CQ, Bai YL, Qiao GF, Lu YJ, Yang BF. Homocysteine inhibits potassium channels in human atrial myocytes. Clin Exp Pharmacol Physiol 2007; 34: 51-55.

23. Cai BZ, Zhao LM, Wang N, Liu JQ, Zhu SL, Meng FY, Zhou HY, Lu YJ, Ai J, Yang BF. Bone marrow mesenchymal stem cells upregulate transient outward potassium currents in postnatal rat ventricular myocytes. J Mol Cell Cardiol 2009;47(1):41-48

24. Wang Y, Xu H, Kumar R, Tipparaju SM, Wagner MB, Joyner RW. Differences in transient outward current properties between neonatal and adult human atrial myocytes. J Mol Cell Cardiol 2003; 35: 1083-1092.

25. Koopmann TT, Bezzina CR, Wilde AA. Voltage-gated sodium channels: action players with many faces. Ann Med 2006; 38:472-482.

26. Wagner MB, Wang Y, Kumar R, Tipparaju SM, Joyner RW. Calcium transients in infant human atrial myocytes. Pediatr Res 2005; 57:28-34. 